\title{
Spectroscopic Studies on the Nature of the Active Centres in Anionic Polymerization
}

\author{
S. BYWATER \\ Chemistry Division, National Research Council of Canada, \\ Ottawa, K1A 0R9 Canada.
}

(Received April 15, 1980)

\begin{abstract}
The evidence provided on active centre structure by NMR studies on models of ionic polymerization systems is described. It is also shown that near UV optical spectroscopy studies can also be of value in some specific cases. The application of such studies to the elucidation of the mechanism of stereospecific polymerization is discussed.
\end{abstract}

KEY WORDS Anionic Polymerization / Stereospecific Polymerization / UV

Spectroscopy / Active Centres /

Spectroscopic studies on low-molecular-weight analogues of the active centres present in ionic polymerization give valuable insight into active centre structure. A detailed knowledge of the structure of ion-pairs is necessary to obtain information on the processes which lead to specificity in ionic polymerization processes. The most valuable tool is NMR spectroscopy (both ${ }^{1} \mathrm{H}$ and ${ }^{13} \mathrm{C}$ ) ${ }^{1,2}$ although some pertinent information can sometimes be obtained from UV-visible spectroscopy. Resonance-stabilized carbocations and carbanions show characteristic absorption bands in the near ultraviolet region, ${ }^{3}$ whose positions are sometimes sensitive to configuration. In this case measurements can be made even on actual active polymer molecules of high molecular weight as well as models, for unlike NMR spectroscopy no contribution is obtained from the mass of inactive monomer units in the polymer chain. The NMR method is restricted to models which have a degree of polymerization of one or two. Otherwise the spectra will be too complex to interpret and largely composed of signals deriving from the in-chain units which are of no interest in the present application. Only in proton NMR studies can this be circumvented by using deuterated-monomer units in-chain with normal monomer in the active centre. ${ }^{4}$ Resolution, however, is often worse than in shorter chain models.

In ${ }^{13} \mathrm{C}$ NMR spectroscopy, a major effect on chemical shift is produced by excess or deficiency of electron density at a particular carbon. The shifts of attached hydrogens move in a parallel fashion. Carbons with a net positive charge resonate at much lower field compared with neutral carbons of the same hybridization and equivalent position in the molecule. Those with a net negative charge resonate at higher field under the same conditions. For example the charged carbons of the isopropyl and $t$ butyl cations absorb at $>300 \mathrm{ppm}^{5}$ (Figure 1) (All shifts mentioned are downfield of TMS), a region well downfield of that expected of $\mathrm{sp}^{2}$-hybridized carbons. With isopropyl or $t$-butyllithium on the other hand, the corresponding carbon resonates at about $10 \mathrm{ppm} .{ }^{6}$ Unfortunately in this case the hydridization is obscure. Figure 1 also shows ${ }^{13} \mathrm{C}$ NMR shifts of the diphenylmethyl cation ${ }^{7}$ and anion-pair, ${ }^{8}$ one of the few cases in which a direct comparison can be made. The differences of chemical shift at the $\alpha$-position are very large and the shifts of the ortho and para carbons are downfield in the cation and upfield in the anion of the normal position in uncharged aromatic compounds $(\sim 130 \mathrm{ppm})$. The shifts at meta and ipso positions are far less affected. These results indicate that as expected charge (positive or negative) is concentrated at $\alpha$, ortho and para positions. Closer analogs to ions present in actual polymerization processes are provided by the $\alpha$-methylbenzyl cation and the potassium dimer of $\alpha$-methylstyrene 


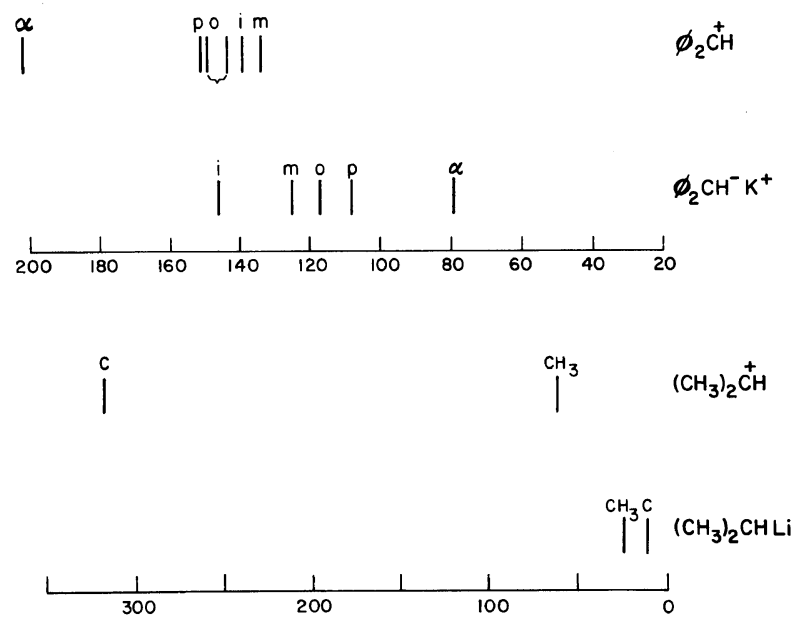

Figure 1. ${ }^{13} \mathrm{C}$ NMR shifts of the diphenylmethyl cation and the diphenylmethyl-potassium ion-pair. Shifts in ppm downfield from TMS.<smiles>[Z][C@](C)(CC)CC(C)C</smiles>

The resonances of the $\alpha$-methylbenzyl cation occur at $\mathrm{C}_{\alpha} 230 \mathrm{ppm}, \mathrm{C}_{\text {para }} 162 \mathrm{ppm}$, and $\mathrm{C}_{\text {ortho }} 144,155$ $\mathrm{ppm}^{9}$ whereas in the potassium dimer of a $\alpha$ methylstyrene they are at $\mathrm{C}_{\alpha} 78 \mathrm{ppm}, \mathrm{C}_{\text {para }} 88 \mathrm{ppm}$, and $\mathrm{C}_{\text {ortho }} 107.5,102 \mathrm{ppm} .{ }^{6}$ Charge declocalization is again extensive at the ortho and para positions. In both cases this results in partial double bond character in the $\mathrm{C}_{\alpha}-\mathrm{C}_{i p s o}$ bond. Ring rotation is restricted and slow on the NMR time scale producing differences of chemical shift at the two ortho positions. Under the conditions used for the measurements the free cation is being observed, but the carbanions are investigated in solvents such as THF where ionic dissociation is small so that anionpairs are principally present. Charge distribution between $\alpha$ and ring positions depends on solvent and counter-ion; in this case more charge being delocalized into the ring with potassium dimer than with the lithium dimer. ${ }^{6}$ This produces a higher barrier to rotation in the former case about the $\mathrm{C}_{\alpha-}$ $\mathrm{C}_{i p s o}$ bond. No rotation of the aromatic ring can be observed with the potassium dimer up to $\sim 65^{\circ} \mathrm{C}$, but in the lithium case rotation is only frozen-out at $-10^{\circ} \mathrm{C}^{10}$ Actual barriers to rotation have been measured for similar compounds, i.e., the $t$ - butyllithium adducts of styrene and $\alpha$-methylstyrene

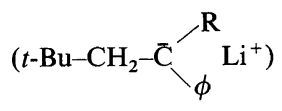

in THF. They are 12 and 14 kilocalories per mole respectively. ${ }^{11}$ In general, therefore all the styryltype ions have a $\mathrm{sp}^{2}$-hybridized structure with restricted rotation of the aromatic ring.

Because of the much lower stability of carbocations, these have only been observed spectroscopically at low temperatures and under very special conditions, i.e., in very strong acid solution. Carbanions (strictly their ion-pairs) can, however, be studied over a range of temperatures and solvents, essentially under conditions used for actual polymerization. Compounds modelling the active centres in diene polymerization are particularly valuable. These are generally formed by adding $t$-butyllithium to isoprene or butadiene in equivalent amounts. ${ }^{12,13}$ Essentially a model stable active polymer of degree of polymerization only slightly greater than unity can be formed. It can be purified by reaction with $\mathrm{HgCl}_{2}$ to form the corresponding mercury compound which can be distilled to remove the small amounts of higher oligomers. ${ }^{6}$ The mercury compound can then be reconverted to the lithium (or other alkali metal) compound by contacting with finely divided alkali metal (or its films). In this way the compounds 
Table I. Charge distribution at the $\alpha-, \beta-, \gamma$-positions in

$t$-Bu- $\mathrm{CH}_{2} \mathrm{CH}-\stackrel{\mathrm{M}^{+}}{\mathrm{C}} \ddot{\mathrm{H}}-\mathrm{CH}_{2}{ }^{-}$

(Units, fraction of an electron)

\begin{tabular}{lccccccc}
\hline & $\alpha$ & $\beta$ & $\gamma$ & & $\alpha$ & $\beta$ & $\gamma$ \\
\hline Li/benzene & 0.79 & -0.13 & 0.22 & Na/THF & 0.65 & -0.12 & 0.49 \\
Li/ether & 0.69 & -0.13 & 0.35 & K/THF & 0.59 & -0.11 & 0.53 \\
Li/THF & 0.69 & -0.15 & 0.40 & Rb/THF & 0.55 & -0.11 & 0.53 \\
& & & & Cs/THF & 0.51 & -0.12 & 0.52 \\
\hline
\end{tabular}<smiles></smiles>

have been studied extensively. ${ }^{14}$ As with the styrene derivatives, the charge distribution varies with counter-ion and solvent. Estimations are given in Table I. These are based on unit electronic charge producing an upfield shift of $\sim 120 \mathrm{ppm}$ in ${ }^{13} \mathrm{C}$ NMR as estimated from allyllithium or potassium and assume $\mathrm{sp}^{2}$ hybridization of all three carbons. Undoubtedly there are small effects other than charge on chemical shift which have been neglected but the total charge measured ( $0.88-1.02$ electron) lends confidence to the view that a semi-quantitive estimation of charge distribution has been achieved.

NMR measurements on the diene polymerization models (isoprene and butadiene) reveal another interesting phenomenon. Both cis and trans forms of the active centre exist in equilibrium. ${ }^{12,13}$ In hydrocarbon solvents the preferred form is trans for the lithium derivative of both dienes although some cis form can be detected. ${ }^{13,15}$ In polar solvents, however, the cis form is gnerally preferred ${ }^{14}$ (Table II). The factors which influence cis/trans preference are not entirely clear. It should be remembered that

Table II. Percentage of trans configuration in<smiles>[Y16]CC1=C([R])C1CCC(C)C</smiles>

at equilibrium

\begin{tabular}{lrlr}
\hline & \multicolumn{2}{c}{$\mathrm{R}=\mathrm{CH}_{3}$} & \multicolumn{2}{c}{$\mathrm{R}=\mathrm{H}$} \\
\hline Li/benzene & $65 \%$ & Li/benzene & $77 \%$ \\
$\mathrm{Li} /$ ether & $25 \%$ & Li/ether & $75 \%$ \\
$\mathrm{Li} / \mathrm{THF}$ & $\sim 0 \%$ & $\mathrm{Li} / \mathrm{THF}$ & $35 \%$ \\
$\mathrm{Na} / \mathrm{THF}$ & $\sim 0 \%$ & $\mathrm{Na} / \mathrm{THF}$ & $22 \%$ \\
$\mathrm{~K} / \mathrm{THF}$ & $\sim 0 \%$ & $\mathrm{~K} / \mathrm{THF}$ & $\leq 10 \%$ \\
\hline
\end{tabular}

the lithium compounds are associated in hydrocarbon solvents which may have some effect on the equilibrium position. The presence of a $\beta$-methyl substituent tends to decrease the trans percentage at least with the lower alkali metals, but the $t$-butyl group substituted at the $\delta$-position has little effect in the cases where information is available. Its replacement by another diene unit leads to the same equilibrium position. This is a necessary requirement if we wish to use these models to predict the behaviour of real polymer chains. A bulky group substituted at the $\gamma$-position does, however, have a pronounced effect, making the trans form highly preferred even in tetrahydrofuran. ${ }^{16}$

The two isomers can also show somewhat different absorptions in optical spectroscopy. ${ }^{17,18}$ The predominantly trans form can be retained in THF by transfer from hydrocarbon solvents at low temperature. Only around $-40^{\circ} \mathrm{C}$ does the system become mobile enough to change to the THF preferred configuration. ${ }^{12}$ Changes in the near-UV absorption characteristic of delocalized allylic ions occur during this process which enables the characteristic spectra of pure cis and trans forms to be established (Figure 2). This data can be used in the determination of the configuration of the active centre in real polymerization systems where the NMR method cannot be used. It cannot be automatically assumed that equilibrium is maintained during polymerization. The new active centre formed immediately after monomer addition may not be formed in its equilibrium configuration. ${ }^{17,19,20}$

Besides styrene, its derivatives and the dienes, acrylate monomers are susceptible to anionic polymerization. Model compounds for NMR studies cannot be prepared in this case by the simple addition of butyllithium to the monomer because of 


\section{S. BYWATER}

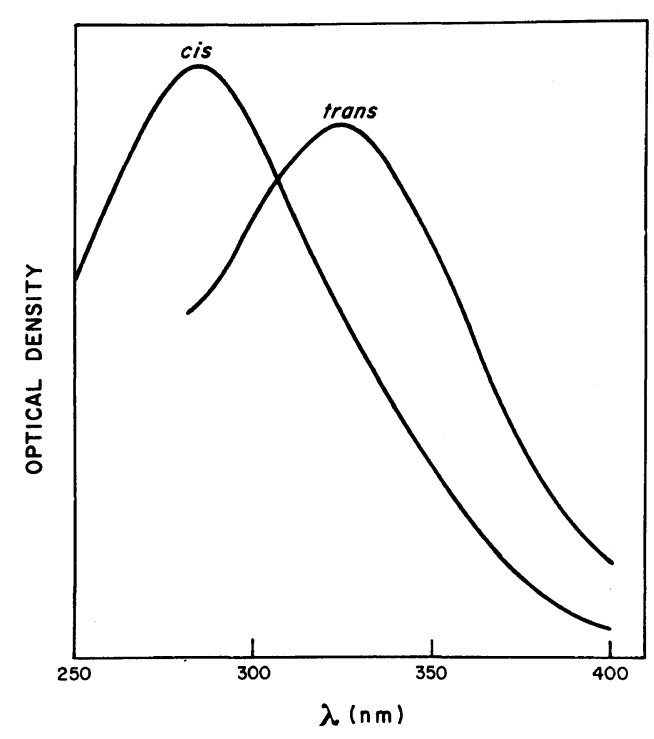

Figure 2. Near-UV absorption spectra of the cis and trans forms of the polybutadienyllithium in THF at $-40^{\circ} \mathrm{C}$.

side reactions. Instead, suitable models can be obtained by metallation of methyl isobutyreate by $N$-lithio-diisopropylamide or similar alkali metal derivatives of amines. ${ }^{21,22}$ The alkali metal derivatives

$$
\begin{aligned}
& \mathrm{CH}_{3} \backslash \mathrm{M}-\stackrel{\mathrm{M}^{+}}{\mathrm{CH}_{3}} \underset{\mathrm{C}}{\mathrm{CH}_{3}}>\mathrm{O} \\
& \mathrm{OCH}_{3}
\end{aligned}
$$

studied in THF by ${ }^{13} \mathrm{C}$ NMR spectroscopy again give evidence of planar $\mathrm{sp}^{2}$-hybridized structures. ${ }^{22}$ The two methyl groups are non-equivalent at least up to room temperature. Decomposition prevents studies at higher temperatures. Estimation of charge distribution between carbon and oxygen is difficult in such hetero-allylic systems. Evidence has been presented in similar alkali metal compounds (Potassium salts of crotonaldehyde and phenylacetone) ${ }^{23,24}$ that an oxygen atom carries more of the charge than a similarly situated methylene group as intuitively expected. Lack of rotation of the methyl groups on the NMR time scale suggests a degree of double bond character in the

$$
\stackrel{\mathrm{CH}_{3}}{\mathrm{CH}_{3}}>\mathrm{C} \cdots \mathrm{C}
$$

bond as does the marked downfield chemical shift of the methyl-substituted carbon on metallation. This change in chemical shift is considerably greater $(\sim 10$ ppm more) for the lithium salt than for the potassium salt which can be interpreted as being caused by a greater fraction of the charge residing on carbon with the heavier alkali metals. ${ }^{22}$ Replacement of one methyl group by an ethyl group enables distinct $c i s$ and trans forms to be observed. The proportion of the two isomers changes somewhat with counter-ion but there is no strong preference for one form under any conditions.

Similar experiments have been carried out by Hogen-Esch and co-workers ${ }^{25}$ on models related to the polymerization of 2-vinylpyridine. Metallation products of 2-ethylpyridine were investigated in THF. $\mathrm{sp}^{2}$ hybridization of the carbanion-pair is as usual indicated with distinct cis and trans forms present. Unlike the acrylate series, the cis/trans ratio is very dependent on counter-ion. The trans-form is favoured especially with lithium (16/1) but less so with the other alkali metals. Strong cation solvating agents modify the isomer ratio quite markedly.

Spectroscopic measurements have increased our knowledge of the nature of the active centres. This should be useful in clarifying polymerization mechanism, particularly the phenomenon of stereoregulation. Use of the model anion studies has been made in the field of diene polymerization. It should be emphasized, however, that knowledge of the preferred equilibrium configuration is not sufficient, information on isomerization rates is also necessary since a newly formed active centre is not necessarily formed in its equilibrium configuration. This phenomenon occurs in diene polymerization in both polar and non-polar solvents and determines the final cis/trans ratio in the polymer. ${ }^{19,20}$ In this case competition between rearrangement to the stable form and freeezing the structure by new monomer addition occurs, resulting in changes in microstructure with polymerization conditions. The higher vinyl contents observed in diene polymerization in ether solvents must also be related in some way to the charge distributions given in Table II, which show in these solvents higher charge at the $\gamma$ position. There must be superposed an additional specific counter-ion effect to explain the variation with counter-ion.

For vinyl polymerization the connection between ion-pair structure and polymer structure is more complex since in this case it is the steric relationship between one monomer unit and its neighbours 
which determines stereostructure. Simple one monomer unit models do not therefore give sufficient information and longer chain models are necessary. Invariably it has been shown that $\mathrm{sp}^{2}$ hybridization occurs in the alkali-metal derivatives under consideration. In dimers two possible forms of the active centre exist in principle, with the counter-ion on one side or other of the plane of the anion. One may be preferred in a dimer for example for steric reasons or because of enhanced interaction of the cation with polar groups on the penultimate unit. Some information is presently available on two-unit models of 2-vinylpyridine and methyl methacrylate. In the former case this relates to structures formed in the reaction of dimer anion-pairs with methyl iodide in THF. With lithium and sodium as counterions the product was overwhelmingly meso in configuration, ${ }^{25}$ but the structure was more mixed with the heavier alkali metals. This has been explained in terms of enhanced stability with smaller ions of the diastereomer

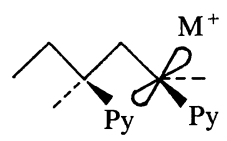

together with cation side attack of methyl iodide. In the case of methyl methacrylate experiments on actual "living" dimers have been made with several counter-ions in THF ( $\mathrm{Li}, \mathrm{Na}, \mathrm{K})$. Their ${ }^{13} \mathrm{C}$ NMR spectra show evidence for the presence of two species whose proportion depends on counter-ion. ${ }^{26}$ In this case, however, it appears these are the cis and trans forms of the active centre rather than diastereomers. No determinations were possible in non-polar solvents because of solubility problems.

It should, of course, be emphasized that in vinyl polymerization even if a stable configuration of the chain can be established, other information is necessary. Besides the possibilities of inversion, the direction of approach and alignment of the incoming monomer is important. The latter problem can be elucidated by use of monomers specifically deuterated in the methylene group. ${ }^{25,27} \mathrm{~A}$ basic knowledge of the stable configuration in multi-unit models is, however, a necessary part of the study of stereoregulation.

\section{REFERENCES}

1. F. . Schué, D. J. Worsfold, and S. Bywater, J. Polym. Sci., $B, 7,821$ (1969).

2. W. H. Glaze and P. C. Jones, J. Chem. Soc. Sect D, 1434 (1969).

3. S. Bywater, Pure Appl. Chem., 4, 319 (1962).

4. M. Morton, R. D. Sanderson, and R. Sakata, Macromolecules, 6, 181 (1973).

5. G. A. Olah and A. M. White, J. Am. Chem. Soc., 91, 5801 (1969).

6. S. Bywater, P. Lachance, and D. J. Worsfold, $J$. Phys. Chem., 79, 2148 (1975).

7. G. A. Olah, P. W. Westerman, and J. Nishimura, $J$. Am. Chem. Soc., 96, 3548 (1974).

8. Y. Takahashi, Y. Kondo, R. Asami, and Y. Inoue, Org. Magn. Reson., 6, 580 (1974).

9. G. A. Olah, P. W. Westerman, and D. A. Forsyth, $J$. Am. Chem. Soc., 97, 3419 (1975).

10. S. Bywater and D. J. Worsfold, J. Organomet. Chem., 33, 273 (1971).

11. S. Brownstein and D. J. Worsfold, Can. J. Chem., 50, 1246 (1972).

12. F. Schué, D. J. Worsfold, and S. Bywater, Macromolecules, 3, 509 (1970).

13. W. H. Glaze, J. E. Hanicak, M. L. Moore, and J. Chaudhuri, J. Organomet. Chem., 44, 39 (1972).

14. S. Bywater and D. J. Worsfold, J. Organomet. Chem., 159, 229 (1978).

15. S. Brownstein, S. Bywater, and D. J. Worsfold, Macromolecules, 6, 715 (1973).

16. M. Schlosser and J. Hartmann, J. Am. Chem. Soc., 98, 4674 (1976).

17. A. Garton and S. Bywater, Macromolecules, 8, 694 (1975).

18. A. Garton, R. P. Chaplin, and S. Bywater, Eur. Polym. J., 12, 697 (1976).

19. D. J. Worsfold and S. Bywater, Macromolecules, 11, $582(1978)$

20. A. Garton and S. Bywater, Macromolecules, 9, 697 (1975).

21. L. Lochmann and D. Lim, J. Organomet. Chem., 50, 9 (1973).

22. L. Vancea and S. Bywater, Preprints, Makro Mainz, IUPAC 26th International Symposium on Macromolecules, Mainz, September 1979, No. 1, p 140.

23. G. J. Heiszwolf and M. Klosterziel, Recl. Trav. Chim. Pays-Bas, 86, 807 (1967).

24. G. J. Heiszwolf and M. Klosterziel, Recl. Trav. Chim. Pays-Bas, 86, 1345 (1967).

25. W. L. Jenkins, C. F. Fong Tien, and T. E. Hogen Esch, Pure Appl. Chem., 51, 139 (1979).

26. L. Vancea and S. Bywater, unpublished data.

27. W. Fowells, C. Schuerch, F. A. Bovey, and F. P. Hood, J. Am. Chem. Soc., 89, 1396 (1967). 